\title{
Inteligência Emocional e o Perfil dos Líderes de uma Cidade na Serra Gaúcha
}

\author{
Marília Gomes Pôrto ${ }^{1}$ \\ Lucas Tartarotti ${ }^{2}$ \\ Leonardo da Costa Bagattini ${ }^{3}$
}

\begin{abstract}
Resumo: Este estudo conceitua a liderança, descrevendo suas características e evolução histórica, e qual é o seu papel nas organizações. Traz como objetivo geral identificar o perfil de líderes nas empresas da cidade de Guaporé-RS, pertencente à Serra Gaúcha, a partir das características observadas pela Inteligência Emocional. Como forma de condução, faz uso de uma pesquisa de natureza quantitativa de nível exploratório, com procedimentos bibliográficos e estratégia de pesquisa Survey. Através da pesquisa é possível observar que o estilo que os pesquisados se autodescrevem é o Treinador, definido como o mais eficaz quando as pessoas se encontram aptas e conscientes de seus pontos fracos e desejam verdadeiramente evoluir. O sucesso desse estilo depende tanto do liderado que deseja efetivamente ser treinado como da disposição do líder em contribuir para a evolução do colaborador.
\end{abstract}

Palavras-chave: líder; Psicologia Organizacional; inteligência emocional.

\section{Emotional Intelligence and the Profile of the Leaders of a City in Serra Gaúcha}

Abstract: This study conceptualizes leadership, describing its characteristics and historical evolution, and what is its role in organizations. Its general objective is to identify the profile of leaders in companies in the city of Guaporé-RS, belonging to Serra Gaúcha, from the characteristics observed by Emotional Intelligence. As a way of conducting, it makes use of a research of quantitative nature of exploratory level, with bibliographic procedures and research strategy Survey. Through research you can see that the style that respondents describe themselves is the Coach, defined as the most effective when people are fit and aware of their weaknesses and truly want to evolve. The success of this style depends as much on the leader who really wants to be trained as on the willingness of the leader to contribute to the employee's evolution.

Keywords: leader; Organizational Psychology; emotional intelligence.

\section{Inteligencia Emocional y el Perfil de los Líderes de una Ciudad en Serra Gaucha}

Resumen: Este estudio conceptualiza el liderazgo, describiendo sus características y evolución histórica, y cuál es su papel en las organizaciones. Su objetivo general es identificar el perfil de líderes en empresas de la ciudad de Guaporé-RS, pertenecientes a Serra Gaucha, a partir de las características observadas por la Inteligencia Emocional.

\footnotetext{
${ }^{1}$ Bacharel em Administração pela Universidade de Caxias do Sul (UCS). E-mail: mgporto@ucs.br.

${ }^{2}$ Doutorando em Administração pela Universidade de Caxias do Sul (UCS); Mestre em Administração (UCS); Bacharel em Administração (UCS); Experiência como docente na Universidade de Caxias do Sul; experiência como docente na TecSerra Cursos Técnicos; experiência como docente na QI Faculdade \& Escola Técnica; consultoria para a empresa varejista Ditesta \& Daihead; experiência como representante comercial na HS Consórcios - Grupo Herval; experiência como vendedor na empresa Drinks2u, Dublin - Irlanda; experiência como auxiliar administrativo na Universidade de Caxias do Sul - UCS; experiência na área de atendimento no protocolo acadêmico da UCS; Intercâmbio de estudos em Dublin - Irlanda durante o período de um ano (20152016). E-mail: lucas.t10@hotmail.com.

${ }^{3}$ Especialista em Administração Financeira pela Universidade de Caxias do Sul (UCS); Bacharel em Administração (UCS); Professor Auxiliar Especialista Nível II da Universidade de Caxias do Sul. Tem experiência na área de Administração, com ênfase em Planejamento Estratégico, Finanças e Negócios Internacionais. E-mail: lcbagattini@ucs.br.
} 
Como forma de realizar, utiliza una investigación exploratoria de naturaleza cuantitativa, con procedimientos bibliográficos y encuesta de estrategia de investigación. A través de la investigación, puede ver que el estilo que los encuestados se describen a sí mismos es el Entrenador, definido como el más efectivo cuando las personas están en forma y son conscientes de sus debilidades y realmente desean evolucionar. El éxito de este estilo depende tanto del líder que realmente quiere ser entrenado como de la voluntad del líder de contribuir a la evolución del empleado.

Palabras clave: líder; Psicología Organizacional; inteligencia emocional.

\section{Introdução}

A ciência tem evoluído constantemente em diferentes áreas de conhecimento, como psicologia, psiquiatria e também neurociência, com essa evolução foi se descobrindo maneiras diversas de determinar o sucesso das pessoas, e não diferente, o sucesso das organizações. Como objeto de estudo, a inteligência emocional, conhecida como QE (quociente emocional) entre os estudiosos, tem sido usada para determinar o potencial das pessoas para aprender as bases do domínio próprio, autoconhecimento e controle das emoções. O controle emocional tem potencial de trazer mudanças significativas, seja no ambiente profissional, seja na vida pessoal, uma vez que a pessoa passa a compreender sua responsabilidade sobre seu próprio bem-estar e dos que o cercam, utilizando habilidades aprendidas para promover uma transformação cultural e social no ambiente que vive ou trabalha (GOLEMAN, 2007).

Goleman (2014) define a Inteligência Emocional como a "capacidade de identificar os nossos próprios sentimentos e os dos outros, de nos motivarmos e de gerir bem as emoções dentro de nós e nos nossos relacionamentos”. Para Goleman, a Inteligência Emocional é a grande responsável pelo sucesso ou insucesso das pessoas. Exemplificando, o estudioso aponta que a maioria das situações de trabalho e da vida são envolvidas por relacionamentos entre os indivíduos. Isso conclui que pessoas com qualidades de relacionamento humano como gentileza, compreensão e afabilidade - têm maiores chances de alcançar o sucesso e, por meio dessa percepção, começou-se a discutir o tema relacionado à Inteligência Emocional dentro das organizações formais.

O interesse crescente sobre o tema da Inteligência Emocional conecta-se com as rápidas mudanças sociais e organizacionais decorrentes da evolução dos interesses e reivindicações dos indivíduos (DULEWICZ; HIGGS, 2000). Como resultado, a mudança veloz de processos de trabalho, tecnologias, objetivos e demandas de mercados, características deste novo tempo da globalização e do conhecimento, acarretou em novos 
requisitos: criatividade, flexibilidade - pessoal e organizacional -, orientação à transformação, inovação constante e foco nos resultados (NEVES; COSTA, 2012).

Para esta pesquisa, o tema envolve o estudo da Inteligência Emocional e as Lideranças nas organizações. Assim, o problema de pesquisa se define como: Qual o perfil dos líderes em empresas da cidade de Guaporé-RS a partir das características observadas pela Inteligência Emocional? O objetivo geral deste estudo é identificar os perfis de líderes em empresas da cidade de Guaporé-RS a partir das características observadas pela Inteligência Emocional.

Nestes tempos dinâmicos, os cenários econômico, social, de mercado, de relações internacionais, de tecnologias, entre outros, estão em constante mudança. A situação das empresas tende a ser mais volátil - assim, uma vantagem competitiva que poderia ser defendida por décadas no passado, atualmente pode ruir em pouco tempo. O mundo globalizado relaciona as nações tanto em aspectos positivos como negativos. Assim, crises em outros lugares do mundo podem acarretar impactos relevantes em empresas nacionais. Nesse contexto, a Inteligência Emocional ganha relevância, principalmente para as lideranças das organizações que precisam tomar decisões em momentos de caos e incerteza.

Este estudo surge justamente para suprir essa lacuna de relacionar a Inteligência Emocional com a liderança. Sabe-se que muitas vezes o foco das organizações é na inteligência técnica dos profissionais. Treinamentos focam em habilidades úteis para a rotina do profissional. Entretanto, em um mundo dinâmico, o trabalho muda rápido, porém a necessidade de Inteligência Emocional, principalmente dos líderes, continua presente, independentemente da situação em que a empresa está exposta. Assim, esta pesquisa busca contribuir nesta relação tão importante que é liderança e Inteligência Emocional.

Com esta pesquisa espera-se entender os perfis de liderança de um grupo de líderes de uma região do Rio Grande do Sul, para a partir disso relacionar estes perfis de liderança com a Inteligência Emocional. Sabe-se que a autocompreensão do líder é importante para o desenvolvimento da Inteligência Emocional. Portanto, esta relação entre perfil de liderança e Inteligência Emocional pode contribuir para o desenvolvimento das organizações.

\section{Fundamentação Teórica}


Esta pesquisa se orienta pela construção de um referencial teórico que contempla as definições de liderança, líderes e suas características e a evolução histórica desses fatores no contexto organizacional, possibilitando identificar os traços dos diversos perfis de liderança e a partir disso observar o perfil de liderança por meio das características observadas pela Inteligência Emocional.

\subsection{Liderança}

Minicucci (1995) define liderança como influência interpessoal numa situação por intermédio do processo de comunicação, para que seja atingida uma meta, ou metas específicas. O comportamento do líder tem o poder de influenciar a equipe nas atitudes e no desempenho. O modelo de liderança é que mostra a performance dos líderes e dos liderados no sucesso das metas da organização.

Existem atributos para uma boa liderança: senso de missão; confiança em sua própria capacidade de liderança; amor e dedicação ao que faz, às pessoas e à organização em que trabalha; abnegação; disposição para rejeitar comodismos e capacidade de suportar os problemas inerentes da função; bom caráter, ser honesto, enfrentar a realidade e situações difíceis, não temer as críticas; ser sincero e confiável; competência na função, entender e estar familiarizado com o trabalho exercido e com a organização como um todo; discernimento, diferenciar o que é ou não importante, bom senso, tato e critério para avaliar o futuro e planejar em função deste; energia, um líder precisa chegar cedo e sair tarde do trabalho, sofrerá pressões de diversos problemas e para enfrentá-los precisa de energia ilimitada, boa saúde e força moral (BITTEL, 1982). Segundo Crainer (2000), existem escolas de pensamento sobre liderança, abaixo algumas delas podem ser descritas:

Teoria do Grande Homem: essa teoria teve predominância no final do século XX, quando foi fundamentada na ideia de que a pessoa já nasce com as habilidades de liderança de forma inata, o que torna-se algo inexplicável para grande maioria, sendo então elevados ao nível de herói. Esse conceito também é encontrado na fala de Bennis (1996), o qual afirma que as habilidades de liderança são inatas, ou seja, o homem já nasce com essa condição, sendo que apenas poucos são escolhidos para exercer seu papel de líder. 
Teoria dos Traços: assemelhando-se à teoria do Grande Homem, esse conceito de liderança defende a ideia de que certas características pessoais permitiriam a alguns homens acesso ao poder. Para a Teoria dos Traços, era possível encontrar traços generalizados nos líderes que os distinguiam dos não líderes (BERGAMINI, 2005).

Teoria Contingencial ou do Comportamento: essa teoria foi elaborada por Fiedler, o qual diferencia a existência de dois tipos principais de estilos de liderança: aquele que pode ser considerado como orientado para a tarefa e aquele que é orientado para relacionamento. Seguido por estudos eventuais - a liderança começou a ser observada como um processo proveniente da relação existente entre o líder e outras pessoas. Logo, são descartadas certas características que agregam para o sucesso virtual dos líderes e engrandecida sua capacidade em ajustar os comportamentos às exigências momentâneas. $\mathrm{O}$ mais ressaltante nessa teoria é o argumento de que é preciso abster tanto da situação em que se encontram os grupos quanto dos aspectos pessoais do líder ao analisar sua liderança, pois o desempenho organizacional está amarrado não somente ao estilo do líder, mas também aos fatores influenciados por ele (FIEDLER, 1967).

Outro ponto relevante é o debate sobre a formação das lideranças futuras. Conforme Meneghetti (2017), os países mais desenvolvidos do mundo apresentam desafios no campo pedagógico no que se refere em poder ter lideranças futuras. Isso porque contaminou-se a possibilidade de os jovens serem protagonistas na história. Nota-se, por exemplo, um plágio comportamental e científico dos EUA por indivíduos de outras nações, principalmente uma psicologia de massa, de mercado. Ou seja, existe um padrão de liderança copiado e disseminado pelo mundo que talvez não seja adequado para todas as nações ou em todos os casos.

\subsection{Grade gerencial de Blake e Mouton}

Segundo Maximiano (2008), a grade é uma tabela de dupla entrada que possui dois eixos, onde o vertical representa a ênfase nas pessoas e a horizontal representa a ênfase na produção. A grade tem como estrutura uma visão bidimensional sobre liderança, valorando os dois estilos, tal combinação de estilo gera cinco possibilidades principais. $\mathrm{O}$ foco na produção e nos resultados é uma das dimensões do Grid. A segunda dimensão é o foco nas pessoas (BLAKE; MOUTON, 2000). 


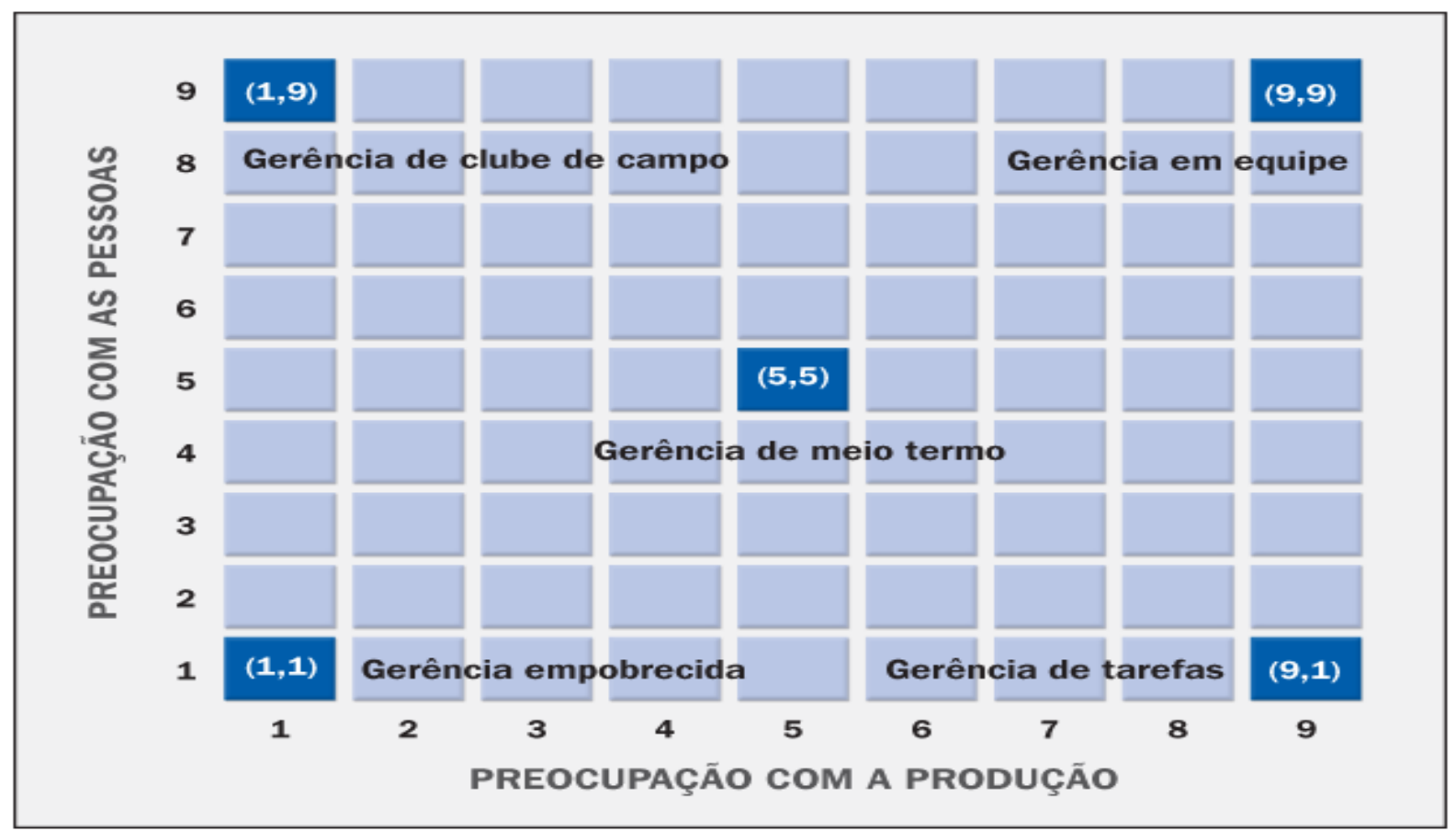

Figura 1: Grade gerencial de Blake e Mouton. Fonte: adaptado de Blake e Mouton (2000).

Dos extremos ao ponto médio da grade acima surgem os estilos de liderança: Líder tarefa: orientado para a produção $(9,1)$; Líder pessoas: orientado para as pessoas $(1,9)$; Líder negligente: não preocupa-se com tarefas e nem com pessoas $(1,1)$; Líder equipe: orientado simultaneamente para pessoas e tarefas $(9,9)$ e Líder "meio-termo": medianamente preocupado com resultados e pessoas $(5,5)$.

\subsection{Psicologia Organizacional}

A Psicologia Organizacional observa o trabalho como uma ferramenta para realização pessoal e como instrumento de produção, tendo como foco de estudo a linha que divide o indivíduo, o trabalho e a sociedade, analisando o comportamento, o desenvolvimento, a realização e, por final, o sofrimento. Para Schette (2005), o RH da maioria das empresas deve expandir seu foco de desempenho, transformando a área de Treinamento em um espaço que beneficie a formação e a especialização de todos os colaboradores. 
“A aprendizagem é um processo psicológico essencial para a sobrevivência dos seres humanos no decorrer de todo o seu desenvolvimento" (ZANELLI, 2004, p.237). É importante ressaltar as duas linhas sobre aprendizagem que se originaram dentro da área da Psicologia no século XX. A linha behaviorista salienta a mudança de comportamento que permanece de forma relativa e duradoura como produto onde há interação do indivíduo com o ambiente. E a linha cognitivista (teorias S-O-R) ressalta que a mudança de comportamentos também ocorre como fruto da interação com o ambiente, dessa forma esta interação antes finaliza-se em processos mentais ou no alcance de conhecimentos, habilidades e atitudes - "CHAs", que podem sofrer interferência a partir das mudanças.

Conforme Zanelli (2004), atualmente essas são as teorias da aprendizagem que passaram a dominar o cenário da Psicologia Organizacional e do Trabalho. Baseando-se como referência a magnitude da aprendizagem no contexto organizacional, é nítido enfatizar que a educação correlaciona toda influência que o ser humano adquire dentro do ambiente social durante a sua vida, discernindo-a de acordo com as leis, regras e valores sociais atuais. Pode-se ressaltar vários tipos de educação: educação religiosa, política, cultural, profissional, etc, porém a profissional será motivo de preocupação por parte dos gestores e das organizações. Como ações organizacionais que utilizam uma tecnologia instrucional ou são deliberadamente arranjadas, visando à aquisição de CHAs para superar deficiências de desempenho no trabalho, preparar empregados para novas funções, adaptar os recursos humanos para a introdução de novas tecnologias ou promover o livre crescimento dos membros de uma organização (ZANELLI, 2004, p. 241).

A Psicologia Organizacional tem muito o que agregar para o desenvolvimento das organizações, porém, segundo Schette (2005), é preciso adquirir legitimidade. É necessário ter recursos, acessos ao poder formal e apoio das pessoas com capacidade de influenciar as outras ao seu redor. Zanelli (2004) diz que é preciso que os psicólogos organizacionais possuam um entendimento mais amplo do quadro de transformações que marcam o momento presente, e uma ação voltada à ética administrativa e política com uma visão de mundo norteada pela rigorosidade, pesquisa, competência e disponibilidade para interagir.

\subsection{Inteligência emocional}


Inteligência Emocional é a capacidade de criar motivações para si próprio e de persistir num objetivo apesar dos percalços; de controlar impulsos e saber aguardar pela satisfação dos seus desejos; de se manter em bom estado de espírito e de impedir que a ansiedade interfira na capacidade de raciocinar; de ser empático e autoconfiante (GOLEMAN, 2007, p. 58).

Quanto maior for o nível de consciência da liderança sobre suas próprias emoções, ou seja, quanto maior o autoconhecimento, mais fácil será identificar e compreender os sentimentos dos demais que o cercam. Pode-se definir a Inteligência Emocional como o equilíbrio entre o lado emocional e o lado racional, ou como a habilidade de lidar com as emoções de forma assertiva e inteligente.

Weisinger (2001) afirma que a Inteligência Emocional é simplesmente o uso inteligente das emoções - isto é, fazer intencionalmente com que as emoções trabalhem a seu favor, utilizando-as como um auxílio para determinar seu comportamento a seu raciocínio de forma a aprimorar seus resultados.

Segundo Goleman (2001), a Inteligência Emocional possui cinco competências emocionais e sociais básicas que são classificadas por ele como: autopercepção, autorregulamentação, motivação, empatia e habilidades sociais.

Autopercepção diz respeito ao indivíduo compreender e manipular de modo consciente e confiante suas emoções para desenvolver um comportamento correto diante da situação enfrentada; Goleman (2001) afirma que as pessoas que possuem essa competência sabem que emoção estão sentindo e o porquê; conseguem se dar conta das conexões entre seus pensamentos e sentimentos; conseguem reconhecer como seus sentimentos afetam diretamente seu desempenho e, por fim, possuem uma percepção direcionadora de seus valores e objetivos.

Autorregulamentação refere-se ao nosso autocontrole, ou seja, a nossa habilidade de utilizar nossas emoções e impulsos de modo a facilitar o bom desenvolvimento diário de nossas vidas; segundo Goleman (2001), as pessoas com essa competência gerenciam bem seus sentimentos impulsivos e emoções aflitivas; mantêm-se compostas, positivas e impassíveis, mesmo em momentos difíceis; pensam com clareza e se mantêm concentradas em momentos de pressão.

Motivação é a capacidade do indivíduo de dirigir suas emoções a serviço de um determinado objetivo, ou seja, buscar determinadas oportunidades e direcionar a percepção 
nessa direção; Goleman (2001) define que pessoas com essa competência possuem vontade de realização, que pode ser definida como a capacidade de esforçar-se para melhorar ou satisfazer um padrão de excelência. Tais pessoas estabelecem metas desafiadoras e assumem todos os riscos que já foram previamente calculados; os indivíduos com tal competência possuem iniciativa, que pode ser desenhada como capacidade de demonstrar presteza em

agarrar as oportunidades - eles perseguem as metas além do que lhes são exigido ou esperado, e passam por cima de burocracia e regras quando necessário para que o trabalho seja feito.

Empatia refere-se ao indivíduo perceber seus anseios e os trabalhar de forma positiva para que com isso consiga cultivar sintonia com o maior número de pessoas possíveis, ou seja, é a capacidade fundamental para lidarmos com os relacionamentos e também para competência pessoal. É a habilidade de compreender as outras pessoas por meio da percepção dos sentimentos, necessidades, perspectivas e de possuir um interesse ativo por aquilo que as preocupam. Segundo Goleman (2001), os indivíduos dotados dessa competência são atentos às dicas emocionais e escutam com atenção os outros; mostram sensibilidade e compreendem as perspectivas de outras pessoas; prestam ajuda baseados nas compreensão das necessidades e sentimentos das outras pessoas; atuam na amplificação e no desenvolvimento da capacidade de outras pessoas de modo que reconhecem e premiam os pontos fortes, realizações e evoluções; fazem comentários úteis e identificam as necessidades.

Habilidade social caracteriza-se pela desenvoltura em relacionamentos interpessoais, é a aptidão natural de influenciar nos outros as respostas desejáveis. Conforme Goleman (2001), as pessoas dotadas dessa competência são peritas em persuasão; fazem sintonia fina nas apresentações a fim de atrair quem as ouve; usam estratégias complexas, como a influência indireta, para obtenção de consenso e apoio; orquestram eventos espetaculares a fim de marcar um ponto de vista; lidam de forma direta com questões difíceis; ouvem bem, buscando a compreensão mútua, e se dispõem plenamente a compartilhar informações.

\subsection{Inteligência emocional relacionada à liderança}

Atualmente, para maioria dos executivos, um líder possui diversas funções, como por exemplo, elaborar estratégias, motivar a equipe, criar uma filosofia empresarial, desenvolver 
uma cultura organizacional; quando na verdade se questionarmos um grupo mais experiente de gestores, existe apenas uma função, que é obter resultados.

Segundo Goleman (2014), o mistério sobre o que os líderes podem e devem fazer para motivar a sua equipe é muito antigo. Tal mistério tem movimentado a indústria de "líderes especialistas" onde pessoas com talentos, aptidões e criatividade têm sido caçadas a fim de testar teorias que possam transformar objetivos ousados em realidade, sejam esses estratégicos, financeiros, organizacionais ou até mesmo os três em conjunto.

Goleman (2014) afirma que a liderança eficaz tem se esquivado com destreza de muitas pessoas e organizações, e isso tem acontecido por um motivo que até hoje pesquisas quantitativas não haviam mensurado, que são os comportamentos corretos que trazem resultados positivos. Quanto a isso, Goleman (2014) afirma que lideres especialistas dão consultorias baseados em inferências, experiências e instinto, e algumas vezes essa abordagem atinge seu objetivo e outras não.

Uma pesquisa conduzida pelas empresas de consultoria Hay/McBer, que reuniu uma amostra aleatória de três mil oitocentos e setenta e um executivos escolhidos de um banco de dados com mais de vinte mil pessoas do mundo inteiro, conseguiu desmistificar a liderança eficaz. A pesquisa descobriu seis estilos diferentes de liderança, cada um possuindo sua origem em distintos componentes da inteligência emocional. Individualmente, cada estilo possui um tipo de impacto único e direto sobre o clima organizacional, seja da empresa ou da própria equipe de trabalho, e consequentemente impactou o desempenho financeiro. A pesquisa também identificou um dado muito importante, que os melhores resultados vinham de líderes que utilizavam a maioria dos estilos em um determinado tempo, sem perceber e em medidas diferentes de acordo com cada situação.

GOLEMAN (2014) compara a utilização de cada estilo a um jogo de golfe onde em cada jogada é escolhido um tipo de taco, de acordo com o andamento do jogo. Durante o jogo, o golfista profissional pega e escolhe os tacos baseado no andamento do jogo. Algumas vezes ele tem que ponderar sobre a seleção do taco, outras vezes ele o faz automaticamente. $\mathrm{O}$ profissional percebe o desafio à frente, rapidamente tira a ferramenta correta e elegantemente a coloca para funcionar. É assim, também, que operam os líderes de alto impacto. (GOLEMAN, 2014) 
Referente a essa pesquisa, as grandes novidades são as suas implicações e a descoberta de que cada estilo de liderança provém de diferentes elementos da Inteligência Emocional, pois, primeiramente, ela oferece um entendimento esmiuçado de como os diferentes estilos de liderança afetam diretamente o desempenho e o resultado; segundo, ela indica uma direção clara e objetiva sobre quando um líder deve alternar seu estilo, enfatizando a flexibilidade.

Como mencionado anteriormente, os estilos funcionam de uma forma mais eficaz quando aliados a outros. Goleman (2014) afirma que muitos estudos têm mostrado que quanto mais estilos um líder exibe, melhor é o seu resultado. Líderes eficazes conseguem flexibilizar e alternar os estilos de liderança conforme demanda a situação e esse é um comportamento que pode ser notado em qualquer tipo de organização independentemente de seu tamanho, tempo de existência ou experiência.

Segundo Goleman (2014), líderes que conseguem gerir dessa forma, alternando seu estilo, não agem de forma mecanizada, eles são mais fluidos e perfeitamente sensíveis ao impacto que causam nos outros e, sem perceber, adequam seu estilo para obter um melhor resultado. Goleman explica que pessoas com tal habilidade possuem um sentido mais apurado quando se trata de identificar talentos natos não reconhecidos e motivar pessoas inspirando-as com uma nova energia, ou até conduzir diálogos decisivos quando necessitase de um ultimato, ou melhora ou sai.

São raros os líderes que possuem dentro de suas habilidades comportamentais os seis estilos de liderança. Segundo Goleman (2014), quando apresentada à maioria das organizações a proposta de utilizar essa modalidade de alternativas, a primeira reação é o receio, pois as pessoas se julgam incapazes de fazê-lo ou até mesmo acham que não é natural. Tal reação é compreensível, porém é possível montar uma equipe onde haja integrantes que possuam os estilos que faltam no próprio líder.

Segundo Goleman (2014), para que os líderes ampliem seu repertório de estilos, primeiramente devem compreender quais as competências da Inteligência Emocional faltam serem desenvolvidas, pois cada uma delas esconde uma habilidade de algum estilo; dessa forma, pode-se trabalhar de forma incisiva no desenvolvimento do estilo de liderar.

Existe uma necessidade entre todas as organizações de identificar pessoas aptas a liderar, indivíduos com capacidade de gerir negócios e consequentemente desenvolver novos líderes. Identificar novos talentos não é uma tarefa fácil. Goleman (2014) elencou quatro 
características que qualificam pessoas com esse talento: habilidade de executar: define-se pela capacidade analítica e habilidade de cada indivíduo de colocar ideias em prática; trajetória profissional: Goleman define que bons líderes possuem grande quantidade de trajetórias em suas carreiras profissionais, pois isso demonstra que as pessoas não estão amarradas às minúcias de um cargo; orientação para equipe: Goleman explica que se alguém é capaz de trabalhar pelas pessoas e com outras pessoas, ela está superando o próprio potencial e dos demais; experiências múltiplas: segundo Goleman, uma vasta experiência é um diferencial na hora de escolher um candidato a uma posição de liderança, pois pessoas que veem uma área monopolista geralmente têm dificuldade de se adaptar em ambientes competitivos.

\section{Método}

Segundo Gil (2008), cada pesquisa tem um objetivo específico, por isso distinguemse três níveis: pesquisa exploratória, pesquisa descritiva e pesquisa explicativa. A pesquisa foi estruturada com natureza quantitativa de nível exploratório, com procedimentos bibliográficos e estratégia de pesquisa Survey.

Para essa pesquisa contou-se com a participação de pessoas que atuam em cargos de liderança e gerenciam suas organizações na cidade de Guaporé-RS. Foram convidados líderes a fim de analisar os perfis de liderança relacionando com a Inteligência Emocional. Vale destacar que estatisticamente a amostra não é suficiente para representar todas as lideranças da cidade. $\mathrm{O}$ intuito da pesquisa é analisar esse grupo de líderes para geração de debate sobre o tema.

A amostra não foi definida de forma probabilística, foi definida por conveniência. Um(a) dos autores da pesquisa é natural de Guaporé e por sua ocupação profissional, este autor(a) tem o contato de muitas lideranças da cidade. Este(a) autor(a) enviou o questionário para cinquenta líderes de sua rede de contatos, porém a pesquisa era voluntária, ou seja, o líder tinha a opção de responder ou não. Assim, dos cinquenta líderes contatados, treze líderes aceitaram participar da pesquisa. Uma taxa de retorno de $26 \%$.

Por ser uma cidade de pequeno porte, em torno de vinte e cinco mil e quinhentos habitantes segundo o IBGE, muitos dos líderes afirmaram não participar da pesquisa por preocupação de que outras pessoas da cidade pudessem ter acesso às informações, mesmo a 
pesquisa sendo anônima. Existe, ainda, principalmente em cidades menores, este distanciamento entre empresários e acadêmicos. Porém, ainda assim a pesquisa se mantém relevante tendo em vista a importância dos líderes participantes para a cidade e região.

Pensando na integridade dos líderes e respeitando a solicitação dos mesmos, não se apresenta neste artigo identificação dos líderes e nem das suas respectivas empresas. Como citado anteriormente, o fato de a cidade ser pequena facilitaria a identificação dos líderes participantes, gerando desconforto e ferindo a ética da pesquisa. As informações autorizadas a constar no artigo são:

a) Três líderes de empresas de grande porte. Os outros dez são líderes de empresas de pequeno ou médio porte.

b) Ramo das empresas participantes: indústria de semijoias, indústria de lingerie, indústria metalmecânica e serviço de turismo. Portanto, a maioria dos líderes participantes $(92,3 \%)$ é do setor industrial. Vale ressaltar que a cidade de Guaporé se destaca no estado do Rio Grande do Sul na produção de semijoias.

O processo de coleta de dados se deu por um questionário estruturado com dezoito questões em escala de Likert de cinco pontos enviado por meio eletrônico (Google Forms) entre os dias 27 de agosto de 2018 e 31 de agosto de 2018, totalizando treze questionários válidos. A elaboração do questionário observou as características dos seis perfis de líderes descritos na literatura de Goleman; sendo elaborado um conjunto de três questões que remetem a cada tipo de líder e atribuindo um somatório de pontuação entre 1 e 5 para discordo totalmente e concordo totalmente a fim de permitir graduar a identificação do entrevistado com o perfil de liderança apresentado. O questionário proposto foi validado em um pré-teste realizado no dia 20 de agosto de 2018, antes de ser aplicado aos participantes do estudo.

\section{Discussão e Resultados}

Goleman (2014), através de seu estudo, explica seis estilos de liderança baseados em características levantadas por meio da inteligência emocional. São eles: coercitivo, autoritário, agregativo, democrático, transformacional e treinador. Na cidade de Guaporé foram selecionados treze líderes que desempenham funções gerenciais em suas 
organizações, e através de dezoito perguntas foi possível traçar um aspecto dominante de estilo de liderança na região, com o objetivo de caracterizar o perfil dos entrevistados a partir das características observadas pela Inteligência Emocional.

A partir das dezoito questões elaboradas no questionário estruturado, é possível relacionar os perfis de liderança descritos por Goleman com os perfis dos treze entrevistados, identificando a predominância desses. O questionário, dividido em seis blocos de três questões cada, permite observar nas três primeiras questões a identificação do perfil dos entrevistados com o perfil de líder coercitivo descrito por Goleman (2014) como um líder que espera obediência imediata de seus subordinados de forma inflexível.

A primeira questão "Durante um período de crise, onde é necessária uma decisão estratégica, eu faço sem consultar os membros da minha equipe”. O resultado atribuído para a pontuação total para a pergunta é o somatório dos produtos entre o grau de concordância ou discordância e a quantidade de respostas para cada grau; no caso da primeira questão a pontuação total foi de trinta e dois pontos.

A segunda questão "Sabendo que algo será bom financeiramente para minha empresa, eu imponho essa decisão não importando as consequências" alcançou as respostas totalizando um somatório de trinta e um pontos. A terceira questão "Eu prefiro omitir da minha equipe as decisões estratégicas e no momento oportuno eu as comunico e as pessoas têm a opção de aceitar ou se retirar da equipe." obteve as respostas totalizando um somatório de vinte e nove pontos. O estilo Coercitivo obteve um total geral de noventa e dois pontos, que é a soma dos totais captados pelas três perguntas compostas no bloco.

O segundo bloco possui perguntas que visam a identificar o estilo Autoritário, definido por Goleman (2014) como o líder que mobiliza a equipe na direção de uma visão comum, concentrando-se nos objetivos finais, mas sem dizer como cada indivíduo deve chegar lá.

A quarta questão "Eu tenho uma visão de futuro muito clara para minha equipe, e eu a motivo esclarecendo como o trabalho e função de cada um contribui para o alcance daquilo que foi desenhado" obteve as respostas totalizando um somatório de cinquenta e seis pontos. A quinta questão "Eu consigo dar um feedback claro para minha equipe seguindo um único critério, se o desempenho de cada um ajuda o objetivo geral ou não." alcançou as respostas totalizando um somatório de quarenta e seis pontos. A sexta questão "Em um período de crise ou conflito, eu consigo traçar um novo caminho e incutir nos envolvidos uma nova 
visão de longo prazo. " obteve as respostas totalizando um somatório de cinquenta e quatro pontos.

O estilo Autoritário obteve um total geral de cento e cinquenta e seis pontos, que é a soma dos totais captados pelas três perguntas compostas no bloco.

O terceiro bloco possui perguntas que visam a identificar o estilo Agregativo, definido por Goleman (2014) como o do líder que se concentra nas necessidades de trabalho, mas também se preocupa com as necessidades emocionais dos membros de sua equipe. Ele trabalha de uma forma muito inclusiva e colaborativa, conectando pessoas, construindo relacionamentos e criando harmonia dentro da organização.

A sétima questão "Eu tenho como foco as pessoas, defendo seus valores individuais e suas emoções, deixo as metas e as tarefas em segundo plano.” obteve as respostas totalizando um somatório de trinta e oito pontos. A oitava questão "Eu me empenho em manter os membros da minha equipe felizes sempre crio um clima harmônico entre eles. Com isso eu tenho lealdade" alcançou as respostas totalizando um somatório de cinquenta e três pontos. A nona questão "Na minha equipe existe uma comunicação efetiva. As pessoas se sentem à vontade para compartilhar ideias e inspirações, isso abre espaço para que me critiquem ou elogiem caso julguem necessário". obteve as respostas totalizando um somatório de cinquenta e cinco pontos.

O estilo Agregativo obteve um total geral de cento e quarenta e seis pontos, que é a soma dos totais captados pelas três perguntas compostas no bloco. O quarto bloco possui perguntas que visam a identificar o estilo Democrático definido por Goleman (2014), que incentiva a participação e promove consenso, ouvindo e valorizando as opiniões e críticas de sua equipe.

A décima questão "Eu administro meu tempo obtendo ideias dos membros da minha equipe, assim permito que todos tenham voz e opinião diante de situações que afetam o objetivo de maneira geral" obteve as respostas totalizando um somatório de cinquenta e sete pontos. A décima primeira questão "Eu não me importo de participar de longas reuniões a fim de tomar uma decisão estratégica, pois para mim é muito importante que todos deem uma opinião e que se tenham um consenso." obteve as respostas totalizando um somatório de quarenta e nove pontos. A décima segunda questão "Eu percebo que minha equipe possui preparação e maturidade para que sejam ouvidos e ter suas opiniões acatadas." alcançou as respostas totalizando um somatório de cinquenta e dois pontos. O estilo Democrático obteve 
um total geral de cento e cinquenta e oito pontos, que é a soma dos totais captados pelas três perguntas compostas no bloco.

O quinto bloco possui perguntas que visam a identificar o estilo Transformacional definido por Goleman (2014), que conta com excelência e a autodireção dos componentes da equipe. A décima terceira questão "Obter resultados de forma rápida e efetiva é o meu objetivo principal como líder, pois eu mesmo me empenho para que isso aconteça." alcançou as respostas totalizando um somatório de cinquenta e cinco pontos. A décima quarta questão "Eu tenho habilidade em identificar membros fracos da minha equipe, pois esses não se destacam de forma tão rápida e eficiente como os demais." alcançou as respostas totalizando um somatório de cinquenta e três pontos. A décima quinta questão "Eu acho que feedbacks são desnecessários pois entendo que cada pessoa tem a capacidade de autoavaliação.” alcançou as respostas totalizando um somatório de cinquenta e três pontos. O estilo Transformacional obteve um total geral de cento e trinta e cinco pontos, que é a soma dos totais captados pelas três perguntas compostas no bloco.

O sexto e último bloco possui perguntas que visam a identificar o estilo Treinador definido por Goleman (2014), que ajuda a sua equipe a construir capacidades e desenvolver as habilidades identificadas. Ele atua mais como um mentor que se apresenta de forma consistente e conectando metas pessoais para os da organização. A décima sexta questão "Eu auxilio meus liderados a identificarem seus pontos fortes e fracos." alcançou as respostas totalizando um somatório de cinquenta e oito pontos. A décima sétima questão "Eu dou feedback constante e com isso desafio os membros da minha equipe a atingirem seu melhor" alcançou as respostas totalizando um somatório de cinquenta e cinco pontos. A décima oitava questão "Meus liderados se sentem acompanhados e livres para experimentarem novas opções, existe um diálogo constante." alcançou as respostas totalizando um somatório de cinquenta e sete pontos. O estilo Treinador obteve um total geral de cento e setenta pontos, que é a soma dos totais captados pelas três perguntas compostas no bloco.

Na Figura 2 é possível visualizar como ficaram dispostos os totais obtidos pela pesquisa a respeito dos estilos de liderança baseados nas caraterísticas da Inteligência Emocional dos líderes. 


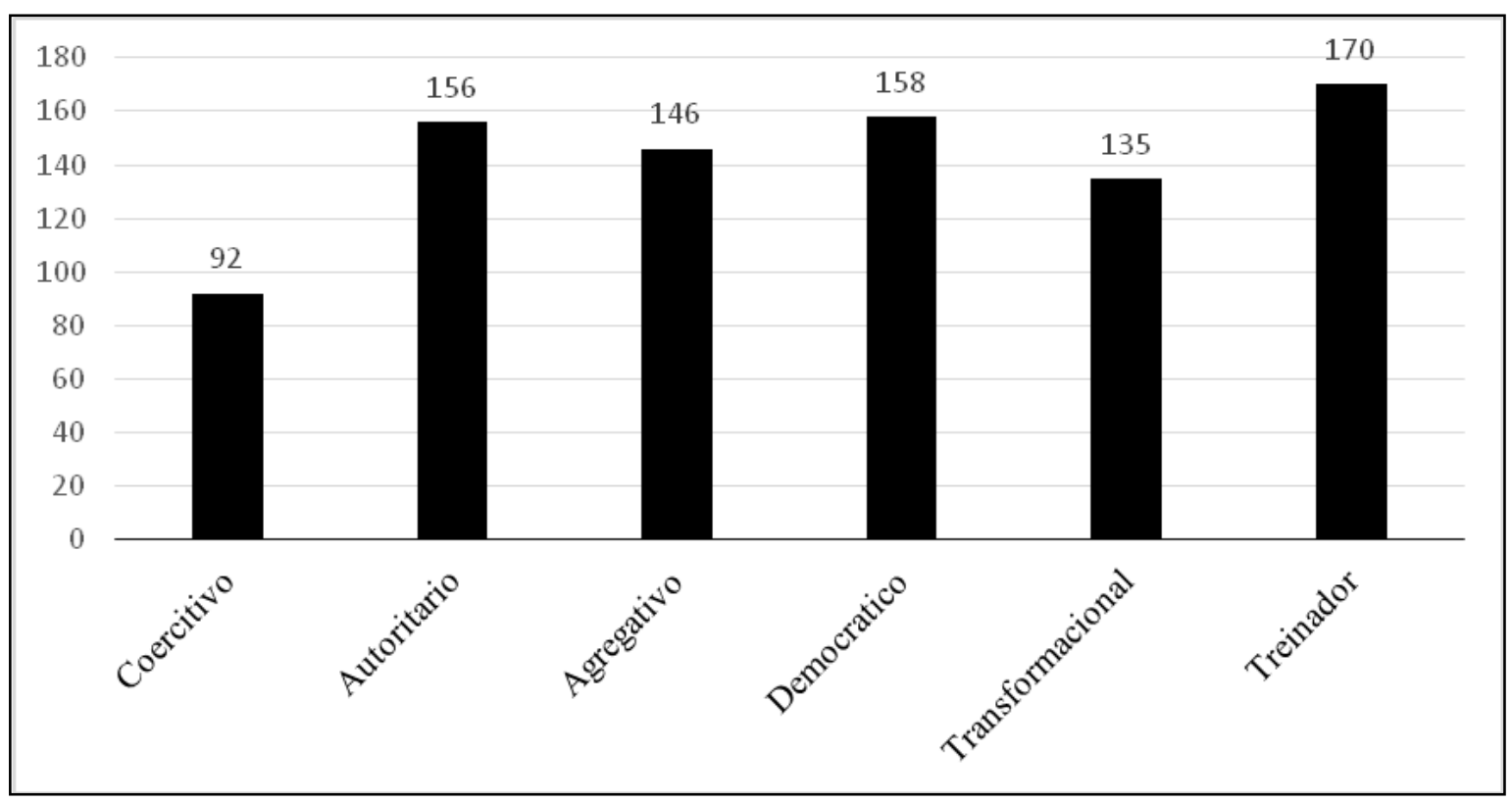

Figura 2: Perfis de liderança. Fonte: elaborada pelos autores (2019).

O resultado das pontuações totais foi obtido a partir da soma dos produtos das quantidades de respondentes para cada questão pelo valor de um a cinco da escala de Likert selecionada por cada respondente. Assim, fica evidente o perfil definido como Treinador para os participantes deste estudo.

\section{Considerações Finais}

Pode-se questionar o que é um líder e qual é o seu papel nas organizações e até mesmo na sociedade, podendo-se obter diversas respostas advindas de várias vertentes e lógicas que foram estudadas, década após década. Com base nessa estrutura, é possível compreender que um líder tem como papel fundamental: definir a estratégia, motivar a equipe, criar uma filosofia coerente e construir uma cultura dentro da organização vinculada. Porém, na prática o que um líder deve fazer é obter resultados, e isso só é possível mediante a maneira como a equipe reage ao seu estilo de gerir, ou seja, de liderar.

Para isso é necessário haver Inteligência Emocional, que é a capacidade de um indivíduo de administrar suas emoções e usá-las a seu favor, além de conseguir compreender as emoções alheias através da empatia, construindo relações saudáveis e fazendo escolhas conscientes, pois as equipes são formadas por pessoas com histórias, culturas e naturezas totalmente diferentes, o que faz com que cada um possua uma visão e interpretação de 
mundo, e é exatamente isso que faz com que cada ser humano seja único e singular. Liderar é saber lidar com um grupo formado por membros distintos e fazer com que trabalhem de forma harmônica e com a mesma meta e visão.

Por meio da pesquisa é possível responder ao objetivo geral deste trabalho, identificar o perfil dos líderes nas empresas da cidade de Guaporé/RS a partir das características observadas pela Inteligência Emocional, e observar que o estilo que os entrevistados se autodescrevem é o Treinador, que no somatório dos resultados obteve a maior pontuação. Tal estilo é definido por GOLEMAN (2014) como o mais eficaz quando as pessoas se encontram aptas e conscientes de seus pontos fracos e desejam verdadeiramente evoluir. $\mathrm{O}$ sucesso desse estilo cabe mais ao liderado que deseja efetivamente ser treinado do que com a disposição do líder em fazê-lo. Porém, quando há pessoas resistentes à mudança, o líder fracassa, ou até quando o mesmo se encontra despreparado para treinar sua equipe.

É importante relembrar que GOLEMAN (2014) explica que os estilos funcionam de uma forma eficiente quando aliados a outros, e que quanto mais estilos um líder exibe, melhor é o seu resultado. Líderes eficazes conseguem flexibilizar e alternar os estilos conforme a situação exige, esse é um comportamento que pode ser observado em qualquer tipo de organização. Essa alternância vai depender tanto da situação e do contexto quanto do perfil da equipe, pois ambos demandam que o líder se adapte para obter um melhor resultado.

O perfil Treinador, que se destacou entre os participantes da pesquisa, tem uma relação especial com a Inteligência Emocional e com o momento atual da sociedade. Buscar desenvolver os colaboradores, explorar o melhor de cada membro da equipe, é crucial no mercado de competição global em que as empresas estão inseridas. Entretanto, o perfil Treinador também contribui em uma questão social, relacional e de qualidade de vida no trabalho. Neste sentido, este estudo é relevante pois contribui para o debate sobre a liderança, relaciona a liderança com a Inteligência Emocional, tão importante nos tempos atuais, e demonstra como o perfil Treinador pode ser uma tendência no cenário atual.

A literatura existente, ampla e acessível, corroborou de forma definitiva para a compreensão e aprofundamento do assunto e os resultados aqui obtidos permitem que se sugira, como estudos futuros, a ampliação da aplicação desta pesquisa para outras cidades dentro e fora do estado do Rio Grande do Sul; permitindo assim, em um futuro, a compreensão do perfil de liderança existente em outras organizações e culturas. 


\section{Referências}

BENNIS, W. A formação do líder. São Paulo: Atlas, 1996.

BERGAMINI, C. W. Psicologia aplicada à administração de empresas: Psicologia do Comportamento Organizacional. 4. ed. São Paulo: Atlas, 2005.

BLAKE, R. R.; MOUTON, J. S. O grid gerencial III. Tradução de Luiza Helza Massena, 5. ed. São Paulo: Pioneira, 2000.

CRAINER, S. Grandes Pensadores da Administração. São Paulo: Futura, 2000.

DULEWICZ, V.; HIGGS, M. Emotional Intelligence. A review evaluation study. Journal of Managerial Psychology, v. 15, p. 341-372, 2000.

GIL, A. C. Métodos e Técnicas de Pesquisa Social. 6. ed. São Paulo: Atlas, 2008.

GOLEMAN, D. Liderança: A inteligência emocional na formação do líder de sucesso. Rio de Janeiro: Objetiva, 2014.

GOLEMAN, D. Os mestres da administração. Rio de Janeiro: Campus/Elsevier, 2007.

GOLEMAN, D. Inteligência emocional: a teoria revolucionária que redefine o que é ser inteligente. Edição revista. Rio de Janeiro: Objetiva, 2001.

MAXIMIANO, A. C. A. Teoria geral da administração: da revolução urbana à revolução digital. 6. ed. São Paulo: Atlas, 2008.

MENEGHETTI, Antonio. Pedagogia Contemporânea: responsabilidade e formação do jovem para a sociedade do futuro. Recanto Maestro: Fundação Antonio Meneghetti, 2017.

MINICUCCI, A. Psicologia aplicada à Administração. São Paulo: Atlas, 1995.

NEVES, A.; COSTA, R. Gestão de Recursos Humanos de A a Z. 2. ed. Lisboa: Editora RH, 2012.

SCHETTE, F. R. O papel da psicologia no desenvolvimento de líderes organizacionais segundo psicólogos e líderes. Tese (Doutorado em Psicologia) - Programa de Pós-graduação em Psicologia. Pontifícia Universidade Católica/Campinas (PUC), Campinas, 2005.

ZANELli, J. C. Psicologia, Organizações e Trabalho no Brasil. Porto Alegre: Artmed, 2004. 